\title{
The Research on Network Platform for Information Processing Based on Public Management
}

\author{
XU Lili, a \\ ${ }^{1}$ Chengdu Polytechnic, Chengdu 610041, China \\ axulili129@163.com
}

\begin{abstract}
Keywords: Public Management, Network Platform, Network Information Security, Information Processing
\end{abstract}

\begin{abstract}
Along with the speeding up of the international network, the wide application of Internet, make people's learning and profound changes have taken place in the way of life, but the Internet information security management issues are also increasingly prominent, along with the network transmission of all kinds of harmful information on the country's political stability, ideology, cultural tradition, social stability to bring a lot of impact and challenges, and a rising trend year by year. This paper reviews in the related theoretical research and practical status quo, based on the perspective of public management to study the problems of network information processing, build a network platform based on public management, making public governance of Internet harmful information possible, with strong social significance.
\end{abstract}

\section{Introduction}

With the rapid development of Internet, online information swelling, harmful or useless information also is gradually increased, some outlaws using the Internet to promote obscenity, pornography, gambling, violence, murder, Using the Internet to spread pornographic materials, carry out pornography transactions. The network harmful information seriously hindered the healthy development of the network virtual social, induce the production of various kinds of illegal and criminal cases, and for Internet users, especially teenagers' produce harm. Control the spread of Internet harmful information, become an urgent task facing the government [1]. Due to the rapid development of our country's present situation and the network problem has not been a good governance of the general environment, network moral norms, quality of Internet users are in urgent need of promotion, network management, it is necessary to further perfect the law and web publishers and network operators need for their own interests, and some of the regulators in absence of public management makes rely on traditional, top-down government governance model for the governance of Internet harmful information has not been able to achieve the objectives of the people want. And by the network gave rise to the formation of civil society, making it possible to public governance of Internet harmful information [2].

At present, the domestic studies in governance of harmful information, or tend mainly to solve from the Angle of legislation or the technical construction, or based on their respective regulatory self-interest, or passive to eliminate the bad influence of Internet harmful information. This article through to the domestic and foreign research results on the network harmful information management of the reference and absorption, based on the study of public management platform for network information processing, to participate in the network harmful information three main body of public management, namely government, operators, social forces, or set made to accord with development trend of the measures, virtuous, positive interaction, implement scientific network information, in order to achieve good governance on the network harmful information public governance objectives. 


\section{Public management in network information processing}

Public management is the management of public affairs, public affairs is the starting point of public management, and determines the inevitable trend of public administration to public management [3]. Network information's influence on social life, is already beyond the scope of simple technology, network asked administration, politics trend has become increasingly apparent, the network anti-corruption campaign in full swing, hot issues more dense network, the network of mass incidents occurred frequently, the network false inciting effect, but it shows the power network information is as a kind of changing our politics, culture and social life [4]. But the spread of network bad information, network, the network of public relations is wanton manipulation of public opinion impact on China's public security is becoming more and more big. Network wave and the spread of false information, the social public opinion and information had a negative effect, creating panic, that cause the reason of mass incidents. And foreign powers use new social tools for cultural infiltration and spreading values of harm national thought, also affected China's cultural security.

The complexity of network public opinion and the quantitative brought difficulties to the government network public opinion management, once the government response to or improper handling can cause Internet users more intense confrontation, and even lead to mass incidents, affect social stability, reduce the government's credibility, and even endanger state security. So the correct view of network information to the public security, the influence of specific policy analyzing public government network information management, to explore the influence of the network information appeared in the process of public administration of public security problem, become a problem we have to think about and face.

So the information security has become an important field national economic security. To construct the network platform for information processing -based on public management, is especially important and urgent. The research on The network platform for information processing -based on public management of network information management of our government administrative means, technology, laws and regulations, The analysis of The industry self-discipline, etc., it can be seen that The government interests imbalances exist in The network information management, policy orientation of negativity, network delay and dispersion of legislation, defects such as network information caused abnormality of public management, can help The government to adjust The more targeted, establish green network public opinion environment, guarantee citizens' freedom of speech and social stability, economic security and national security.

\section{The framework of network platform for information processing based on public management}

With the popularity of the Internet, each public crisis after the incident, will produce different scale network public opinion on the network, the influence of the realistic society spread to the virtual space, combined with the channels of information transmission speed faster and faster, more and more, broader, influence is more and more big, make the public crisis events network public opinion risk management become the major problem faced in the public management. Geared to the needs of the network platform of network information processing is mainly based on public management of network monitoring, analysis and assessment, early warning, putted forward of sampling as well as the formation of historical events and risk management [5]. By analyzing the risk factors of public management, build the subject of public opinion, governance mechanism, heat linkage mechanism, the objective events, the public opinion, official behavior and Internet behavior such as seven dimensions of network public opinion the risk management of public crisis events, as shown in figure 1. 


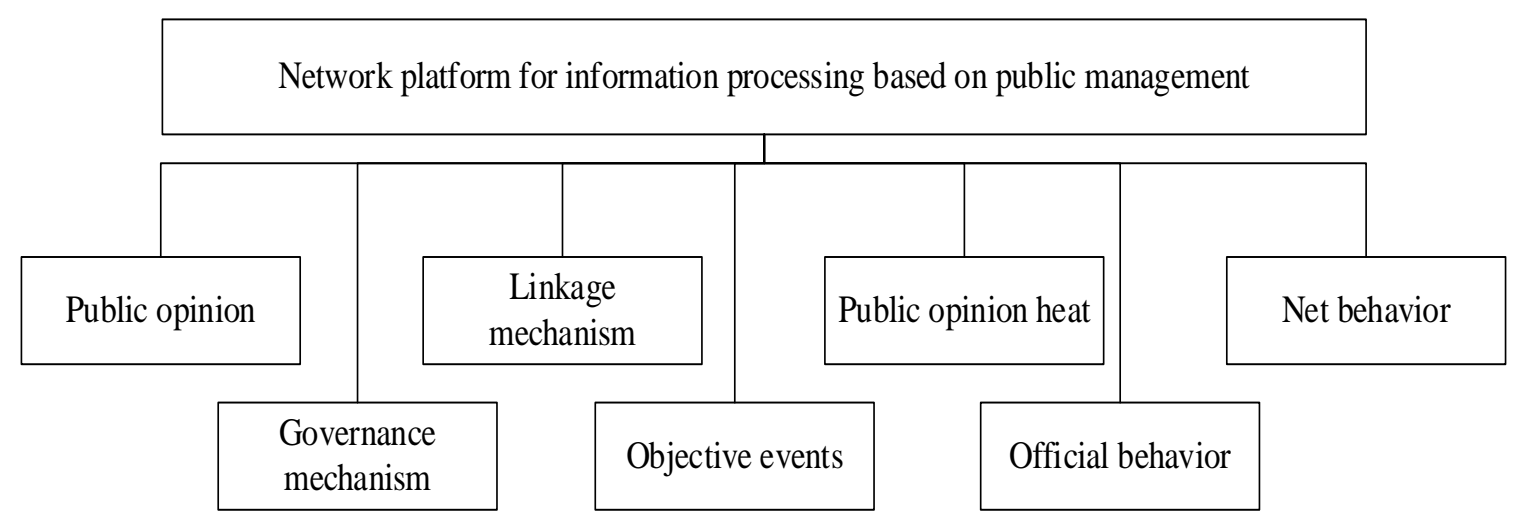

Figure 1. Content of network platform for information processing based on public management

Network platform for information processing based on public management based on e-government Network operation, the system overall framework mainly includes the following several parts: application software platform, supported platform, security system and system operation management specification, as shown in figure 2.

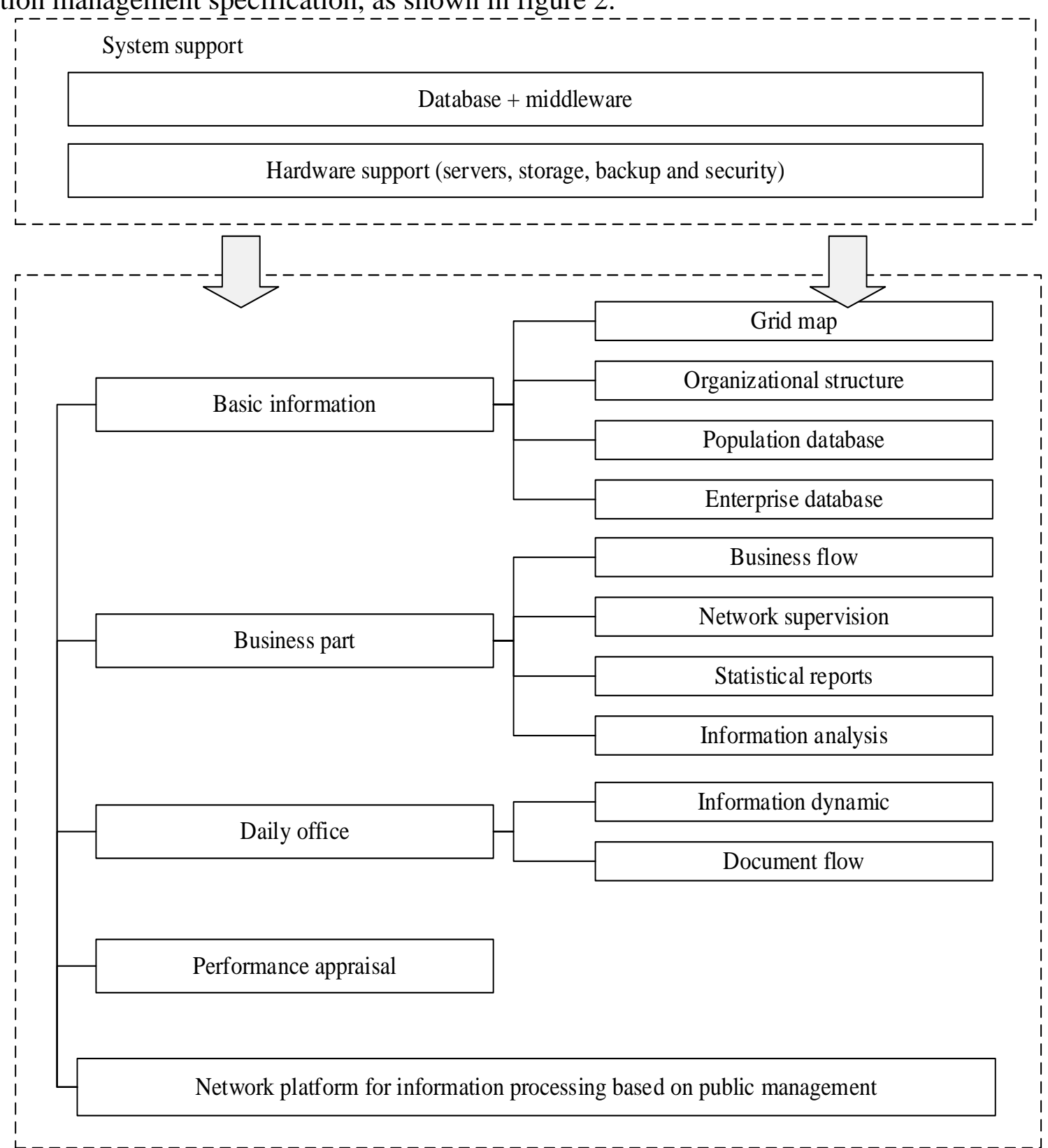

Figure 2. Framework of network platform for information processing based on public management 
Application software platform of the main function module is divided into five most: Firs is the basic information, including grid map, such as organization, population database, enterprise database; Second is part of its business, including business, handling supervision division, statistics, statistical analysis, etc.; Three is the daily work, including dynamic information, document flow and so on; Four is the performance review, including the assessment of the public, customization, of examination score, etc.; Five is the support system, including the project website, system management, SMS platform, instant messaging, etc.

\section{The design of network platform for information processing based on public management}

The design of network platform for information processing based on public management uses virtualization server cluster, making the system have high availability, easy to maintenance and daily management extension. The database server used load balancing technology, multiple servers use "Oracle $11 \mathrm{~g}+\mathrm{RAC}$ " build database load balancing server cluster.

By Oracle RAC build high availability of database system can realize multiple node load balancing, a system of high availability, fault tolerance and seamless switching function; Good scalability at the same time, can easily add or remove nodes, extend hardware resources. Virtualization Server cluster model is composed of multiple servers, application Server virtual cluster middleware use Oracle Web logic Server version for the enterprise to set up load balancing, the core application Server stress can easily increase the virtual machine, share the original application service load effectively.

\section{Conclusion}

Along with the network transmission of various harmful information on the country's political stability, ideology, cultural tradition, social stability to bring a lot of impact and challenges, and a rising trend year by year. This paper reviews in the related theoretical research and practical status quo, based on the perspective of public management to study the problems of network information processing, to explore the role of information in the public management reform process, the application of information technology, network platform for information processing based on public management has been carried on the overall framework design research, based on comprehensively advancing network platform of information processing problems.

\section{References}

[1] Ramgovind S, Eloff M M, Smith E. The management of security in cloud computing[C]//Information Security for South Africa (ISSA), 2010. IEEE, 2010: 1-7.

[2] Zissis D, Lekkas D. Addressing cloud computing security issues[J]. Future Generation Computer Systems, 2012, 28(3): 583-592.

[3] Dikaiakos M D, Katsaros D, Mehra P, et al. Cloud computing: distributed internet computing for IT and scientific research[J]. Internet Computing, IEEE, 2009, 13(5): 10-13.

[4] Hu W, Corke P, Shih W C, et al. secfleck: A public key technology platform for wireless sensor networks[M]//Wireless Sensor Networks. Springer Berlin Heidelberg, 2009: 296-311. Weinhardt

[5] C, Anandasivam D I W A, Blau B, et al. Cloud computing-a classification, business models, and research directions[J]. Business \& Information Systems Engineering, 2009, 1(5): 391-399. 